\title{
Vascular targeted nanotherapeutic approach for obesity treatment
}

This article was published in the following Dove Press journal:

International Journal of Nanomedicine

\author{
Nicole Remaliah Samantha \\ Sibuyi' \\ Mervin Meyer' \\ Martin Opiyo Onani² \\ Amanda Skepu ${ }^{3}$ \\ Abram Madimabe Madiehe \\ 'Department of Science and \\ Technology/Mintek Nanotechnology \\ Innovation Centre, Biolabels Unit, \\ Department of Biotechnology, \\ University of the Western \\ Cape, Bellville, South Africa; \\ ${ }^{2}$ Organometallics and Nanomaterials, \\ Department of Chemistry, University \\ of the Western Cape, Bellville, South \\ Africa; ${ }^{3}$ Department of Science and \\ Technology/Mintek Nanotechnology \\ Innovation Centre, Biolabels Unit, \\ Advanced Materials Division, Mintek, \\ Johannesburg, South Africa
}

\begin{abstract}
Obesity is a global epidemic that poses a serious health concern due to it being a risk factor for life-threatening chronic diseases, such as type 2 diabetes, cancer, and cardiovascular diseases. Pharmacotherapy remains the mainstay for the management of obesity; however, its usefulness is limited due to poor drug efficacy, non-specificity and toxic side effects. Therefore, novel approaches that could provide insights into obesity and obesity-associated diseases as well as development of novel anti-obesity treatment modalities or improvement on the existing drugs are necessary. While the ideal treatment of obesity should involve early intervention in susceptible individuals, targeted nanotherapy potentially provides a fresh perspective that might be better than the current conventional therapies. Independent studies have shown improved drug efficacy by using prohibitin (PHB)-targeted therapy in obese rodents and non-human primates, thus providing a proof of concept that targeted nanotherapy can be a feasible treatment for obesity. This review presents a brief global survey of obesity, its impact on human health, its current treatment and their limitations, and the role of angiogenesis and PHB in the development of obesity. Finally, the role and potential use of nanotechnology coupled with targeted drug delivery in the treatment of obesity are discussed.
\end{abstract}

Keywords: adipose tissue, angiogenesis, nanomedicine, obesity, prohibitin, targeted drug delivery

\section{Introduction}

Obesity has reached epidemic proportions worldwide ${ }^{1}$ and contributes to the increased mortality rates through its association with chronic diseases such as type 2 diabetes (T2D), ${ }^{2}$ cardiovascular diseases (CVDs) ${ }^{3}$ cancer, ${ }^{4}$ and hypertension. ${ }^{5}$ The current treatment of obesity involves lifestyle modification, pharmacotherapy, and surgery. Pharmacotherapy is the cornerstone of obesity treatment and can be used alone or in combination with diet and surgery. ${ }^{6,7}$ However, the drugs used for the management of obesity are tainted by the adverse health risks associated with drug treatment due to their off-target side effects, and lack of specificity which reduces the sensitivity and efficacy of the drugs. ${ }^{8-10}$ Due to adverse effects, many anti-obesity drugs have been removed from the market, leaving only orlistat for long-term treatment of obesity. ${ }^{10-15}$ Moreover, the pharmaceutical drugs are useful for a limited period ( $\leq 2$ years) to avoid detrimental health effects. As such, the drugs cannot be used indefinitely, and discontinuation of treatment is often followed by disease relapse. ${ }^{11}$

Alternative or novel strategies that can treat obesity and sustain the weight loss are required. Such treatments are of utmost importance in health economics as they can reduce the burden of chronic diseases, improve life expectancy, and reduce mortality rates. For this reason, vascular targeted therapy is receiving a considerable amount of attention as a potential anti-obesity therapy. The ability to ferry therapeutic
Correspondence: Abram Madimabe Madiehe

Department of Science and Technology/ Mintek Nanotechnology Innovation Centre, Biolabels Unit, Department of Biotechnology, University of the Western Cape, New Life Science Building, Robert Sobukwe Road, Bellville, 7535, Cape

Town, South Africa

Tel +27 21 9592468

$\mathrm{Fax}+27219593505$

Email amadiehe@uwc.ac.za 
materials directly to pathological cells with no effect on healthy tissues could overcome the drawbacks associated with the conventional pharmacotherapy. ${ }^{16}$ Strategies that target prohibitin (PHB) as a vascular marker for obesity have been explored using a PHB targeting ligand (adiposehoming peptide, AHP) to develop targeted therapy ${ }^{16}$ as well as nanotherapy ${ }^{17,18}$ and are discussed later. Between the two systems, the nanotechnology-based therapy was able to mask the therapy from biodegradation, reduced early drug clearance from the blood system, increased half-life of the nanotherapy, and demonstrated enhanced therapeutic index. These characteristics can be attributed to the unique properties of the nanosystems. ${ }^{17,18}$ The feasibility of the vascular targeted nanotherapy in obesity is reviewed in this paper.

\section{Obesity: a global epidemic}

Obesity is a metabolic and genetic disorder that results from positive energy balance, ${ }^{1,19,20}$ whereby energy intake exceeds energy expenditure for a prolonged period. ${ }^{21}$ If not properly managed, obesity leads to the development of chronic diseases such as $\mathrm{T} 2 \mathrm{D},{ }^{2} \mathrm{CVDs},{ }^{3}$ various forms of cancer, ${ }^{4}$ and hypertension. ${ }^{5}$ These chronic diseases are further associated with adverse health events, increased medical care costs, decreased quality of life, and reduced life expectancy. ${ }^{6,7}$

The prevalence of obesity has increased dramatically worldwide and has become a fast growing epidemic in both developed and developing countries. ${ }^{22}$ The increase in obesity rates can be attributed to gene-by-environment interactions, urbanization, lack of physical activity, and easy access to fast foods. ${ }^{22}$ The epidemic is beginning to show its ugly face even in children. ${ }^{23}$ Globally, women are generally more prone to becoming obese than men. This translates to $70 \%$ of women and $40 \%$ of men classified as either overweight or obese. ${ }^{24,25}$ The WHO classified 650 million adults ( $\geq 18$ years, males and females) as obese and 1.9 billion as overweight in 2016 worldwide. ${ }^{24,25}$ These rates have been steadily growing since 1975 to date as shown in Figure 1. The overall rates indicate that the USA, China, India, and Brazil have the highest population who are either overweight or obese. Korea and Japan have the least obese and overweight population. Similar trends in the prevalence of overweight and obesity in South African adults have been reported, indicating that South Africa (SA) is not immune to this epidemic. ${ }^{24}$ Without strategies to combat these rates, WHO predicts that by $2025,60 \%$ of deaths worldwide will be caused by obesity-associated chronic diseases (CVDs,
T2D, stroke, and cancers). ${ }^{24,25}$ In SA, chronic diseases currently account for $43 \%$ mortality rate. ${ }^{26}$ These projections highlight the urgent need and significance to address the obesity epidemic. . $^{23,24}$

\section{Pathophysiology of obesity}

Physiologically, the white adipose tissues (WATs) play a crucial role in the development of obesity and could serve as the best target for obesity interventions. ${ }^{27} \mathrm{~A}$ better understanding of the development and physiological roles of WAT is important, because this will help to unveil possible new therapeutic approaches for obesity, as well as the prevention of progression to obesity-related diseases.

\section{Adipose tissue (AT) as an endocrine organ}

There are two types of AT in mammals, namely the WAT and brown adipose tissue (BAT). WAT mainly stores excess energy, whereas the BAT serves as an energy dissipating organ as shown in Figure 2. The WATs are responsible for obesity and obesity-induced disorders ${ }^{28}$ hence, the focus of this study is mainly on the WAT and its effect on the development of obesity and obesity-induced diseases. WAT is a loose connective tissue comprised of various cell types held together by a matrix of collagen fibers. The mature, lipid-filled fat cells or adipocytes make up two thirds of the entire tissue. ${ }^{29}$ The remaining one third is made up by pre-adipocytes, endothelial cells (ECs), fibroblasts, mesenchymal stem cells, nerve fibers, monocytes, macrophages, pericytes, and immune cells. ${ }^{29}$ Anatomically, the WATs are located primarily in three major areas: the subcutaneous, intradermal, and intraperitoneal/visceral depots..$^{30}$ The subcutaneous WAT depot is three- to fourfold larger than the visceral depot, but the two function in a coordinated and compensatory manner in the development of obesity and obesity-related diseases. ${ }^{28}$

Physiological functions of WATs include the provision of insulation to internal organs, mechanical support to the organs, and also serve as a storage organ. The WATs store excess energy in the form of triacylglycerols (TAGs) and release it during starvation in the form of free fatty acids and glycerol. ${ }^{31}$ Through the action of insulin, the excess calories are converted into TAGs and stored in the WATs during a chronic positive energy balance. When the energy is in demand, the TAGs are rapidly mobilized via the actions of catecholamines and other lipolytic hormones. ${ }^{29}$ Because it secretes factors such as cytokines (adipokines), growth factors, acylation stimulating protein, plasminogen activator 

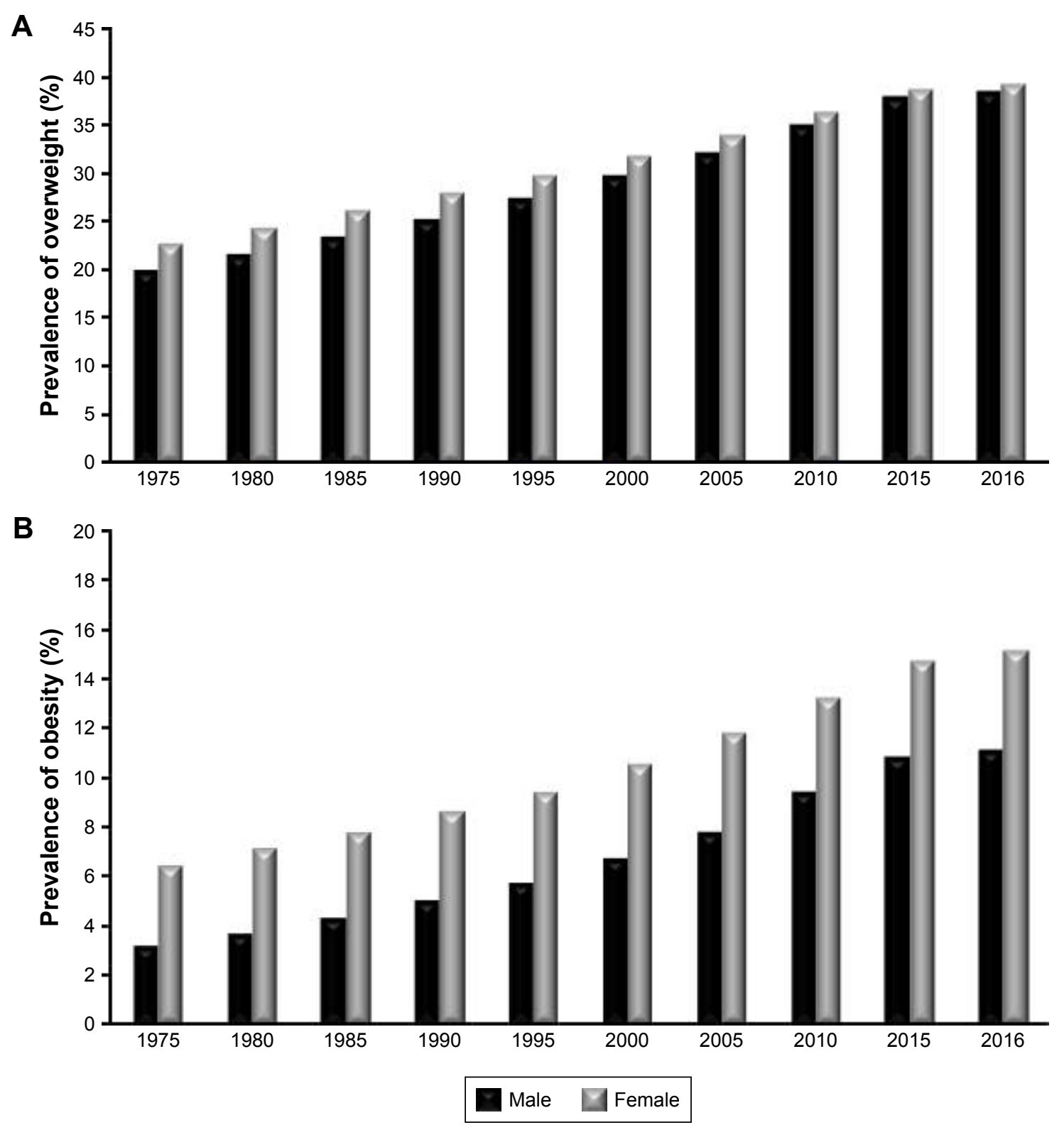

Figure I The global prevalence of overweight $(\mathbf{A})$ and obesity $(\mathbf{B})$ in both male and female adults.

Notes: The data represent 1975 to 2016 statistics for adults aged $\geq 18$ years. Data adapted from: (A) World Health Organization (WHO). Global Health Observatory data repository. Prevalence of overweight among adults, BMI $\geq 25$, age-standardized. Estimates by WHO Region. Available from: http://apps.who.int/gho/data/view.main. REGION2480A?lang=en. Accessed June 4, 2018. (C) Copyright World Health Organization (WHO), 20I7. All Rights Reserved. ${ }^{24}$ And from: (B) World Health Organization (WHO). Global Health Observatory data repository. Prevalence of obesity among adults, BMI $\geq 30$, age-standardized. Estimates by WHO region. Available from: http:/lapps. who.int/gho/data/view.main.REGION2480A?lang=en. Accessed June 4, 20I8. @ Copyright World Health Organization (WHO), 20I7. All Rights Reserved. ${ }^{26}$

inhibitor-1, and lipoprotein lipase, recently, the WAT is recognized as an endocrine organ..$^{31}$ The adipokines and other WAT-secreted factors influence a variety of biological and physiological processes, including metabolism and energy homeostasis. As depicted in Figure 2, various adipokines play different roles within the body such as food intake (leptin), insulin action (adiponectin), glucose metabolism (adiponectin and resistin), and angiogenesis (chemerin). ${ }^{32-35}$ In essence, chronic hypertrophy (increase in size of adipocytes) and hyperplasia (increase in number of adipocytes) in the WAT during the development of obesity results in dysregulated secretion of adipokines and malfunctioning of the WAT. ${ }^{32-37}$ As such, WAT cellular components especially the vascular system can serve as an attractive target for intervention and effective treatment for obesity and its associated disorders..$^{27,33-37,43}$

\section{Conventional treatment of obesity}

Obesity is a chronic disease, and there is currently no treatment that can sustain weight loss for a prolonged period. 


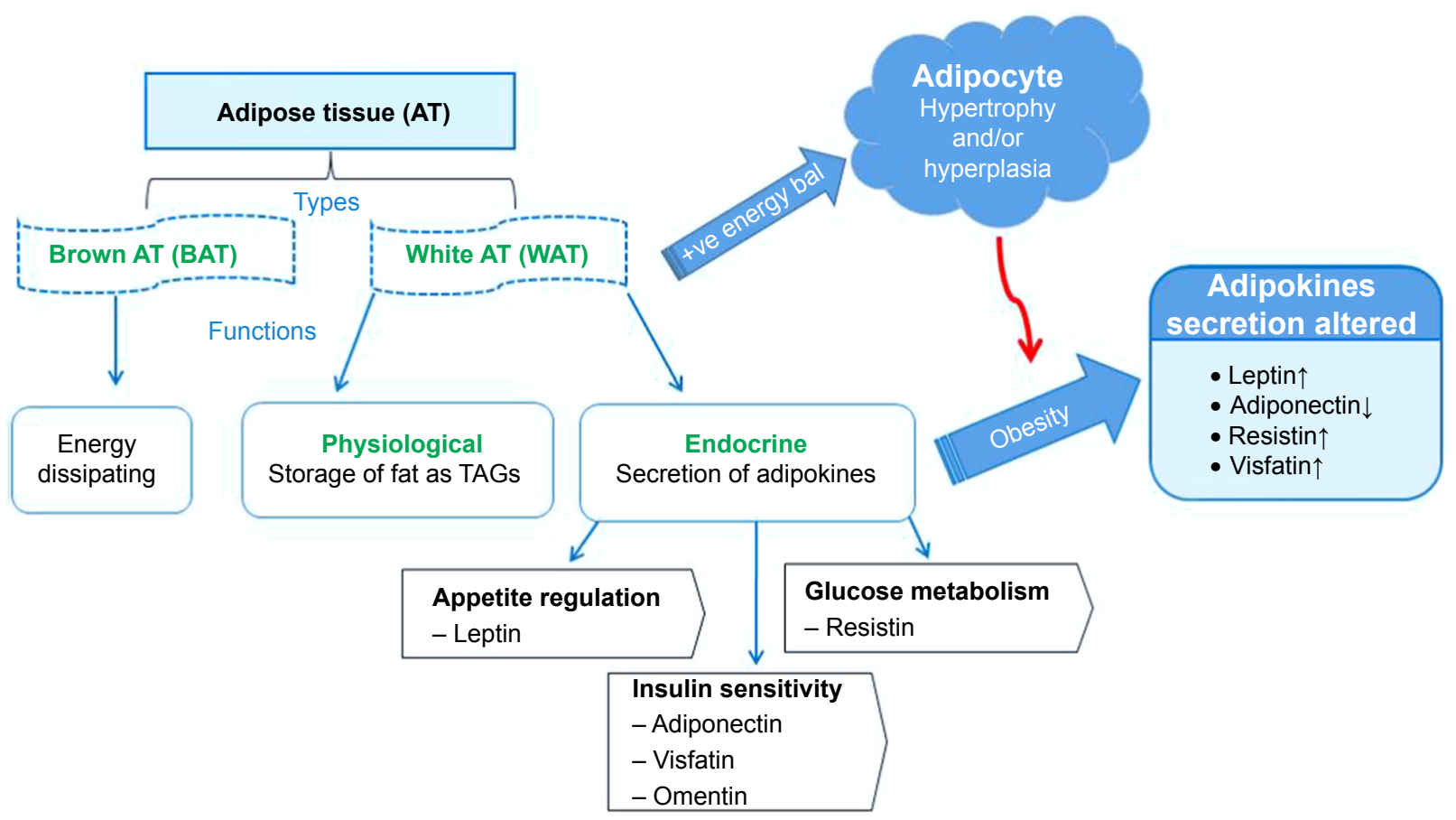

Figure 2 Adipose tissue structure and function and the pathophysiology of obesity.

Notes: During positive energy balance, increase in adipocyte number or size in the WAT leads to the development of obesity and WAT dysfunction. Adipocyte size is reduced during energy restriction or starvation, which leads to normalization of WAT function. $\uparrow$ and $\downarrow$ arrows indicate the increase and decrease of adipokines during obesity development.

Abbreviations: +ve, positive; AT, adipose tissue; bal, balance; bat, brown adipose tissue; TAGs, triacylglycerols; WAT, white adipose tissue.

It can be managed through lifestyle modification, pharmacotherapy, and bariatric surgery. ${ }^{6,7}$ Lifestyle modification involves a combination of behavioral changes, diet, and physical activity. Lifestyle modification on its own can reduce body weight by $7 \%$, improve blood glucose levels and insulin sensitivity, ${ }^{38}$ and thus reduce the risk of CVDs and T2D. ${ }^{39,40}$

Pharmacotherapy is an option for patients with body mass index (BMI) $\geq 27 \mathrm{~kg} / \mathrm{m}^{2}$, with at least one obesity-related chronic disease risk factor. ${ }^{10}$ The treatment is recommended for patients who had gone through lifestyle modification for at least 6 months with no success. It was initially an option for obese adults; however, it is now also prescribed to obese children and adolescents at a greater health risk. ${ }^{6,41}$ The antiobesity drugs are reliable for the period of use, $\leq 6$ months for short term and $\leq 2$ years for long term. ${ }^{10}$ However, discontinuation of medication usually leads to weight regain within a year. ${ }^{11}$ Until 2010, only two drugs were approved by U.S. Food and Drug Administration (FDA) for long-term treatment of obesity: orlistat and sibutramine. Due to negative cardiovascular effects that resulted in the death of patients, sibutramine has since been withdrawn from the market. ${ }^{12-15}$ Sibutramine was successful in reducing body weight in obese subjects since its approval by FDA in 1997. Unfortunately, after its termination only orlistat remains for a long-term management of obesity. ${ }^{10,15}$

Bariatric surgery is recommended for morbidly obese patients $\left(B M I \geq 40 \mathrm{~kg} / \mathrm{m}^{2}\right.$ ) or patients with BMI of $30-40 \mathrm{~kg} / \mathrm{m}^{2}$ and at least one life-threatening health risk associated with obesity. It involves modifying the gastrointestinal tract to reduce caloric intake or nutrient absorption by the body, thereby reducing body weight. ${ }^{42,43}$ Attempts to treat obesity by reducing food intake, with or without anti-obesity drugs are well-known, as are their limitations, difficulties, and general lack of success in maintaining weight loss. ${ }^{10,44}$ Surgical procedures are usually expensive and sometimes associated with gastrointestinal and neurological complications. ${ }^{45,46}$ This clearly predicates the need and urgency to find novel or alternative approaches that could be used to treat and/or prevent obesity at an early stage and improve human health and quality of life. Among the most important goals of obesity treatment are: 1) a preferential reduction of abdominal fat/WAT, 2) an amelioration of obesity-related health risks, 3 ) an improvement in comorbidities and quality of life, and 4) a reduction in mortality rate. ${ }^{6,47}$ Approaches targeted at the root cause of obesity (ie, the pathological WAT) have been shown to be successful in reducing body weight with minimal adverse effects. ${ }^{16,17}$ 


\section{Angiogenesis as a target for vascular targeted therapy}

Angiogenesis, also known as neovascularization, refers to the formation of new blood vessels from pre-existing capillaries. ${ }^{48}$ It is a physiological process that plays an important role in the distribution of oxygen and nutrients to different tissues and organs throughout the body ${ }^{49,50}$ and is crucial for cell growth and development. The blood vessels grow or expand through the interaction between the surrounding cells and the extracellular matrix. This process is activated by the ECs lining the blood vessels. The ECs are actively involved in several regulatory processes within the body and serve as a selective passageway for nutrients, oxygen, and waste removal, to and from the surrounding cells. All physiological angiogenic functions such as the regulation of hemodynamics, vascular remodeling during ovulation, wound healing, and cell growth are executed through the ECs. ${ }^{48,51-55}$ The occurrence of angiogenesis is highly dependent on activation, proliferation, adhesion, migration, and maturation of the ECs. Therefore, altering any of these functions through angiogenic inhibitors will result in blood vessel malformation and reversal of the effects of the disease. ${ }^{52,53,55}$

Angiogenesis is also a classical hallmark of cancer, ${ }^{56,57}$ and its inhibitors have shown great potential as treatment of cancer in preclinical and clinical studies. ${ }^{58}$ These inhibitors are mostly targeted at arresting the growth of vascular ECs, by so doing they prevent cellular growth and metastasis of the fast growing cancer cells. ${ }^{59}$ It is known that the ECs through their lining of blood vessels interact with several cells and provide necessary oxygen and nutrients to these cells. Therefore, prevention of their proliferation will starve the diseased cells leading to their death. Since physiological angiogenesis is minimal in adults, vascular targeting could reduce side effects associated with longterm treatment observed with conventional therapeutic methods. ${ }^{60}$ Moreover, the ECs are always in contact with the blood vessels and the surrounding tissues, and targeting them will increase the accessibility and sensitivity of the systemically administered treatment. Disrupting the functions of ECs will indirectly hamper the survival and growth of the unwanted cells. ${ }^{61}$ The improved efficacy of vascular targeting in various cancers has been demonstrated through preclinical and clinical studies, ${ }^{58,62,63}$ by using anti-angiogenic agents individually ${ }^{69,70}$ or in combination with chemotherapy. ${ }^{58}$

Anti-angiogenic strategies that aim to target biomarkers that are either upregulated or exclusively expressed in pathological vascular systems have been explored for targeted drug discovery and treatment of chronic diseases such as cancer. ${ }^{62,63}$ Diseased tissues and organs in various chronic diseases are highly dependent on their vascular system for growth, proliferation, and survival. Diabetic retinopathy, rheumatoid arthritis, cancer, obesity, and autoimmune disease are some of the diseases in which angiogenesis is switched on. ${ }^{16}$ These diseases are characterized by continuous growth of cells and tissues, ${ }^{63-65}$ as such, treatment strategies that target the vasculature of the diseased cells provide a better approach with sustainable health benefits.

\section{Angiogenesis in obesity}

Angiogenesis is an important factor in the expansion of WATs. ${ }^{65-67}$ AT growth and expansion through either hypertrophy or hyperplasia is highly dependent on the plasticity of the vasculature within this tissue. Hypertrophic and hyperplastic growth of adipocytes are excessive during the development of obesity. This requires an expansion of blood vessels (angiogenesis) to allow nutrients and oxygen to reach the newly formed and expanding adipocytes. ${ }^{66}$

Like cancer, obesity is associated with vascular disorders, ${ }^{53-55}$ and since obesity progression is highly dependent on angiogenesis, it could be reversed by using treatment strategies that inhibit this process. ${ }^{50}$ In obesity, the WATs are highly vascularized in order to support the expanding tissues. ${ }^{66}$ As a result, the WATs are vulnerable at the level of their blood supply due to excessive blood vessel growth. The angiogenic process is mostly vulnerable at the stage of proliferation of the ECs, which is accompanied by the overexpression of certain cell surface receptors during the development of obesity. The receptors could be useful as targets for a therapeutic intervention. ${ }^{49,66}$ Thus, inhibition of angiogenesis in the obese WAT vasculature serves as a plausible therapeutic option for treatment of obesity. ${ }^{65,66}$

Angiogenesis in WATs, like in cancer, is dependent on the balance between proangiogenic and anti-angiogenic factors. Increase in proangiogenic factors in the WATs initiate angiogenesis. ${ }^{67}$ The WATs secrete a number of proangiogenic factors including vascular endothelial growth factor (VEGF)-A, VEGF-B, VEGF-C, hepatocyte growth factor, placental growth factor, fibroblast growth factor-2, angiopoietin (1 and 2), leptin, tumor necrosis factor- $\alpha$, and matrix metalloproteinases. ${ }^{67}$ Since adipogenesis is linked to angiogenesis, inhibition of angiogenesis by targeting of 
proangiogenic factors was shown to regulate WAT mass in animal models of obesity and in vitro. ${ }^{33,67,68}$

The widely studied angiogenesis inhibitors TNP 470, angiostatin, and endostatin ${ }^{69}$ have anti-angiogenic effects in obese subjects and cause reduction in body mass. Different angiogenesis inhibitors have different targets and modes of action. ${ }^{68,69}$ TNP 470 and its analog CDK732, for instance, target methionine aminopeptidase- 2 in the ECs. ${ }^{64}$ Moreover, CDK732 acts by decreasing food intake, the size of adipocytes, fat mass, and body weight in selected rodent models. ${ }^{70}$ Angiostatin and endostatin reduce WAT mass by inhibiting the proliferation of vascular ECs and causing apoptotic cell death. ${ }^{69}$ Although, their mechanism is elusive, vascular remodeling in the WAT of treated mice was observed to validate their (angiostatin and endostatin) anti-angiogenic activity. Their actions do not affect or alter food intake or induce any visible signs of side effects. ${ }^{69}$

Antibodies or ligands that target angiogenic growth factors (such as VEGF-2 receptor) in the WAT vasculature have been shown to inhibit angiogenesis by blocking activities of target receptors when conjugated to apoptotic agents, thus preventing WAT growth in genetic and diet-induced animal models of obesity. ${ }^{67,71} \mathrm{PHB}$ was also explored as an anti-angiogenic target in obesity. Kolonin et $\mathrm{al}^{16}$ discovered that PHB is over-expressed in the WAT vasculature of obese mice and further demonstrated that PHB-targeted pro-apoptotic agent ${ }_{\mathrm{D}}\left(\mathrm{KLAKLAK}_{2}\right.$ or KLA can be delivered into the WAT vasculature of diet-induced obese mice and reverse obesity. The KLA peptide is only toxic to mammalian cells when it is internalized, and once inside the cells, KLA disrupts the mitochondrial function leading to cell death through apoptosis. ${ }^{16}$ Thus, the direct delivery of the therapy to diseased tissues could result in selective targeting that has little or no effect on normal or the surrounding cells or tissues. ${ }^{16}$ For this purpose, angiogenesis proved to be an attractive target for therapeutic intervention for reversal of obesity. Several studies demonstrated the efficiency of antiangiogenic therapy in animal models of obesity as discussed in the following section. ${ }^{16,66}$

\section{PHB and its role in obesity}

The role and function of $\mathrm{PHB}$ in cancer and obesity has been extensively reviewed. ${ }^{72-75} \mathrm{PHB}$ is a $30-\mathrm{kDa}$ multifunctional protein that plays a crucial role in cellular processes such as cell proliferation, endoplasmic reticulum (ER) stress, transcription, apoptosis, and tumor suppression. It is expressed in various cellular compartments including the mitochondria, nucleus, ER, the Golgi complex, endosomes, and plasma membrane. ${ }^{76-78}$ Most of the cellular functions mentioned above are credited to the mitochondrial and nuclear PHB. The mitochondrial PHB sustains the livelihood of the cell by keeping the mitochondrial function intact, while the nuclear PHB regulates cellular transcriptional activity. PHB protects cells from cellular stress generated during mitochondrial dysfunction such as oxidative stress, electrical stimulation, and hypoxic ischemia. When cells are exposed to any of these stressors, the level of PHB is increased, which in turn promotes survival of the cells. Mitochondrial dysfunction has been associated with the development of various diseases including cancer, diabetes, inflammatory diseases, CVDs, neurodegenerative diseases, and reproductive dysfunction. ${ }^{76,77}$

Some of the diseases in which PHB is implicated are shown in Table 1. PHB was reported to be overexpressed in obesity, ${ }^{16}$ cancer, and diabetes and could serve as a potential biomarker for therapeutic intervention. ${ }^{74,78,79}$ Molecules that bind to PHB in various diseases are also highlighted in Table 1; they include AHP, ${ }^{16}$ flavaglines (FLs), ${ }^{80}$ and miR-361. ${ }^{77}$ These ligands were used to deliver therapy or gene silencing molecules to PHB for the treatment of diseases. For instance, knocking down PHB expression in gall bladder cancer (GBC) cells resulted in reduced cancer proliferation, migration, and invasion of surrounding tissues. As such, upregulation of PHB in GBC patients can serve as both prognostic and therapeutic biomarker. ${ }^{79}$ Lentiviral induced PHB overexpression in diabetic cardiomyopathy, demonstrated protective effects in vitro, and improved the myocardial function in vivo. Thus, PHB could be a potential target for the treatment of diabetic cardiomyopathy and T2D. ${ }^{77}$ FLs, a class of plant-derived compounds with medicinal properties including anticancer, anti-inflammatory, cardioprotection, and neuroprotection, were demonstrated to bind to PHB with high specificity. FLs (FL3 and FL37) exerts their cytoprotective effects by binding to molecular targets such as PHB and translation initiation factor eIF4A. ${ }^{78,81}$ The FLs have selective toxicity toward colon cancer cells, bind to PHB in in vitro (Caco-2 BBE cells) and in vivo (chemically induced colitis in mice) models of inflammatory bowel diseases, and inhibit cancer cell proliferation. ${ }^{78}$ PHB is also upregulated in colorectal cancer (CRC) stages I-III. ${ }^{82}$ Targeting PHB with AHP containing a pro-apoptotic (KLA) molecule inhibited proliferation of Caco-2 colon cancer cells. ${ }^{83}$

PHB is also involved in the development of obesity and WAT remodeling. ${ }^{16}$ Since this discovery, PHB was used as a vascular marker for obesity. Independent studies confirmed 
Table I PHB expression and its role in various diseases

\begin{tabular}{|c|c|c|c|c|}
\hline Disease & Model & $\begin{array}{l}\text { PHB targeting } \\
\text { ligand }\end{array}$ & Action/function & Reference \\
\hline \multirow[t]{3}{*}{ Obesity } & C57BL/6] mice & AHP & $\begin{array}{l}\text { - AHP-KLA homed to WAT endothelium } \\
\text { - KLA induced apoptosis in the ECs resulting in reduction } \\
\text { of WAT mass }\end{array}$ & 16,84 \\
\hline & Wistar rats & AHP & $\begin{array}{l}\text { - AHP-AuNPs delivered to the WAT vasculature } \\
\text { - AHP increased target specificity }\end{array}$ & 85 \\
\hline & Rhesus macaques monkeys & $\mathrm{AHP}$ & $\begin{array}{l}\text { - AHP-KLA increased target specificity } \\
\text { - Increased insulin sensitivity } \\
\text { - Reduced body weight }\end{array}$ & 86 \\
\hline \multirow[t]{2}{*}{$\begin{array}{l}\text { Diabetic } \\
\text { cardiomyopathy }\end{array}$} & $\begin{array}{l}\text { Cardiofibroblasts and } \\
\mathrm{H} 9 \mathrm{c} 2 \text { cardiomyoblasts }\end{array}$ & $\begin{array}{l}\text { Lentivirus-mediated } \\
\text { expression of PHB }\end{array}$ & $\begin{array}{l}\text { - PHB overexpression - reduced ROS levels } \\
\text { - Inhibited cytochrome c release and suppressed } \\
\text { cardiomyocyte apoptosis }\end{array}$ & 77 \\
\hline & Sprague Dawley rats & miR-36I & $\begin{array}{l}\text { - PHB overexpression - protected rats against development } \\
\text { of myocardiopathy } \\
\text { - Improved insulin sensitivity }\end{array}$ & 77 \\
\hline $\begin{array}{l}\text { Colorectal } \\
\text { cancer (CRC) }\end{array}$ & Caco- 2 cells & AHP & $\begin{array}{l}\text { - Targeting of AHP-AuNP-KLA enhanced cellular uptake and } \\
\text { efficacy of the treatment }\end{array}$ & 83,85 \\
\hline \multirow[t]{2}{*}{$\begin{array}{l}\text { Inflammatory } \\
\text { bowel diseases }\end{array}$} & $\begin{array}{l}\text { Caco2-BBE cells (human) } \\
\text { and intestinal epithelial } \\
\text { cell-6 (rat) }\end{array}$ & FLs & $\begin{array}{l}\text { - FLs bound to PHB in Caco2-BBE cells } \\
\text { - Displayed prosurvival and anti-inflammatory effects in the } \\
\text { colitis model cell lines } \\
\text { - Reduced proinflammatory cytokines } \\
\text { - Improved mitochondrial function and barrier integrity }\end{array}$ & 80 \\
\hline & $\begin{array}{l}\text { Chemical-induced colitis in } \\
\text { C57BL/6 mice }\end{array}$ & FLs & - Displayed prosurvival and anti-inflammatory effects & 80 \\
\hline $\begin{array}{l}\text { Gall bladder } \\
\text { cancer (GBC) }\end{array}$ & GBC tissues & $\begin{array}{l}\text { Lentivirus-mediated } \\
\text { silencing of PHB }\end{array}$ & $\begin{array}{l}\text { - PHB gene knockdown - inhibited the ERK pathway } \\
\text { activation } \\
\text { - Inhibited the GBC cell proliferation, invasion, and metastasis }\end{array}$ & 79 \\
\hline
\end{tabular}

Abbreviations: AHP, adipose-homing peptide; ECs, endothelial cells; KLA, ${ }_{D}($ KLAKLAK); ; PHB, prohibitin; AuNPs, gold nanoparticles; FLs, flavaglines; WAT, white adipose tissue.

that molecules attached to AHP with amino acid sequence CKGGRAKDC are capable of targeting PHB expressed on the surface of ECs in the WAT of obese mice, ${ }^{16,84}$ rats, ${ }^{85}$ and monkeys. ${ }^{86}$ The role of PHB in the regulation of biological processes leading to the development of diseases implicates PHB as a putative target in drug discovery. Thus, therapeutic strategies that target PHB may unfold the molecular mechanisms and pathogenesis of these diseases. ${ }^{16,77,78,87}$ Targeted nanotherapy is currently being explored as a potential treatment for obesity in a rodent and non-human primate models of diet-induced obesity, by targeting the vascular system that supports the growth of hypertrophic adipocytes. ${ }^{17,18,78,85}$

Disease-associated biomarkers play a crucial role in targeted drug delivery, tissue imaging, and diagnostics. Biomarkers are able to discriminate between a physiological and the pathological state of an organism. ${ }^{88,89}$ These biomarkers are either exclusively expressed or overexpressed by the diseased tissues compared to normal tissues. In biological samples, the concentration of biomarker can be indicative of the presence, absence, or severity of a pathological state. ${ }^{89}$ Targeting can be achieved by using antibodies, peptides, or aptamers that bind to receptors overexpressed by the diseased cells or tissues with high specificity. ${ }^{90,91}$ These receptors could serve as targets for diagnosis and therapeutic intervention in various chronic diseases. ${ }^{16,65}$

\section{Nanotechnology and its application in medical research}

Nanotechnology is a multidisciplinary field of science devoted to the development and application of atoms and molecules at a nanometer scale. ${ }^{92,93}$ Various nanomaterials exist for a wide range of applications in medicine, electronics, water, and so on. Due to their unique and impressive physico-chemical properties, they have been widely used in medicine for diagnosis, drug delivery, and molecular imaging of diseases. The most commonly studied nanomaterials in medicine are liposomes, polymers, silver nanoparticles, gold nanoparticles (AuNPs), and quantum dots (QDs). ${ }^{94}$ These nanomaterials possess unique properties that are important 
in medical research, for example, their large surface area-tovolume ratio allows for multiplexing applications, due to their high payload capacity. ${ }^{94,95}$ The NPs (AuNPs and liposomes) can be used as targeted delivery agents when attached to targeting moieties (antibodies, ligand, and aptamers) or as contrast agents (AuNPs and QDs) to monitor cellular events in biological processes. These NPs are capable of transporting materials in areas that would have been otherwise impossible using bulk materials. ${ }^{92,93}$ Due to their tiny size, the NPs can transverse through cellular barriers and deliver their cargo to the desired target with ease. Nanomaterials ranging from 10 to $20 \mathrm{~nm}$ in size are able to pass through blood vessel walls when administered through intravenous, ${ }^{95,96}$ intramuscular, and subcutaneous routes for biological applications. ${ }^{97}$ While NPs $\leq 50 \mathrm{~nm}$ can penetrate most cellular barriers with ease. ${ }^{98}$

Application of nanotechnology in medical sciences (better known as nanomedicine) has been growing in recent years. Nanotechnology has shown significant impact in cancer research, where a number of nanodrugs (eg, Doxil [Janssen, New Jersey, NJ, USA], Myocet [Teva, Castleford, UK], and Abraxane [Celgene, New Jersey, NJ, USA]) have been approved for clinical treatment of cancer. ${ }^{99}$ The small size of the nanodrug composites allows them to penetrate pathological cells through their leaky vasculature, by taking advantage of the enhanced permeability and retention (EPR) effect on the vasculature of the diseased tissue. ${ }^{95-98,100}$ In a pathological state, EPR is characterized by pathological and excessive angiogenesis and increased secretion of various permeability mediators that can be used as targets for diagnosis or treatment of a disease. These characteristics do not occur in normal tissues or organs and provide an opportunity for more selective targeting of NPs to diseased tissues and allow efficient delivery of therapeutic molecules to the target passively. ${ }^{101}$

Unlike the EPR effect, targeted drug delivery is a better strategy because it directs the delivery of the drug specifically to diseased cells. Targeted delivery can be achieved through the exploitation of disease-specific biomarkers, which discriminate between normal and diseased cells. Active targeting of diseased cells will minimize systemic side effects, thus achieving a balance between efficacy and drug toxicity. ${ }^{93,102}$ Despite the progress made by targeted therapy, there are still concerns due to adverse effects of the therapy. ${ }^{103}$ Research into NP-based drug delivery systems is mounting because these systems can provide better efficacy and limit cytotoxicity to normal cells or tissues. ${ }^{93}$

Liposomes and polymeric NPs have been used successfully as drug delivery agents in clinical studies for targeted delivery of anti-cancer drugs. ${ }^{94,103}$ The drug-targeted NPs can be developed with qualities that can help overcome some of the drawbacks associated with the current therapies, deliver smaller doses of drugs directly to the diseased tissues while monitoring their effect in biological system. The use of such systems as vaccine and chemotherapy carriers for cancer treatment has been extensively studied. ${ }^{104,105}$ The NPs are effective in the prevention of drug degradation and solubility, thus increasing the dosage reaching the diseased tissue. ${ }^{97}$ Biodistribution of the nanomaterials is dependent on their physico-chemical properties such as size, charge, shape, etc. These properties can be manipulated to help increase their circulation times within the body. ${ }^{95}$ Nanomedicine, therefore, offers higher drug efficacy with reduced side effects to the normal and surrounding cells or tissues. Moreover, these effects can be monitored in real time. Thus, while nanotechnology has shown power to revolutionize medicine, ${ }^{94,106,107}$ it can provide an essential breakthrough in the fight against obesity and metabolic diseases through targeted drug delivery. ${ }^{94}$

\section{Potential application of nanotechnology in obesity}

Preclinical studies have covered the basis and paved avenues for vascular targeted nanotherapy as a treatment option for obesity in animal models. ${ }^{18,84,108}$ Figure 3 summarizes the initial steps toward developing a successful vascular targeted nanotherapy, in order to assess the feasibility of the strategy for the treatment of obesity as demonstrated by independent studies. ${ }^{16-18,84,85}$ Targeted nanotherapy can be developed by attaching a targeting peptide and a therapeutic peptide onto the NPs, the NPs serve as drug carriers. The biological effect of the NP-conjugates is validated in vitro and in vivo before they can be considered for clinical use. These systems, especially liposomes and polymeric NPs, have been approved by FDA for clinical trials in cancer therapy. ${ }^{99}, 109-111$

Nanotherapy targeted at ECs in the WAT vasculature for reversal of obesity in preclinical studies has been documented; most of the studies targeted PHB as the WAT vascular marker. ${ }^{17,18,84,85}$ By using PHB-targeting ligand (AHP) conjugated to a KLA peptide (AHP-KLA), the therapeutic peptide (KLA) was able to selectively induce cell death in the WAT vascular system of obese mice. ${ }^{16}$ Disrupting the WAT vasculature led to fat resorption and reduced WAT mass with the consequent reduction of the total body weight and obesity reversal. ${ }^{16}$ Incorporating nanotechnology into the same strategy enhanced the efficacy of the treatment, which was threefold higher than the AHP-KLA bi-conjugate. ${ }^{18}$ 
A

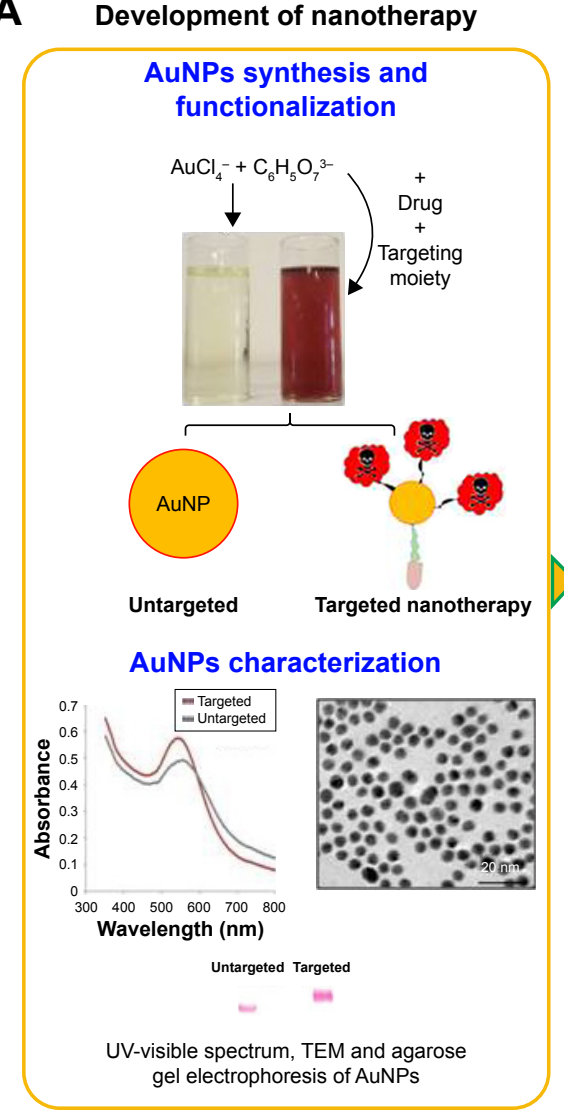

B

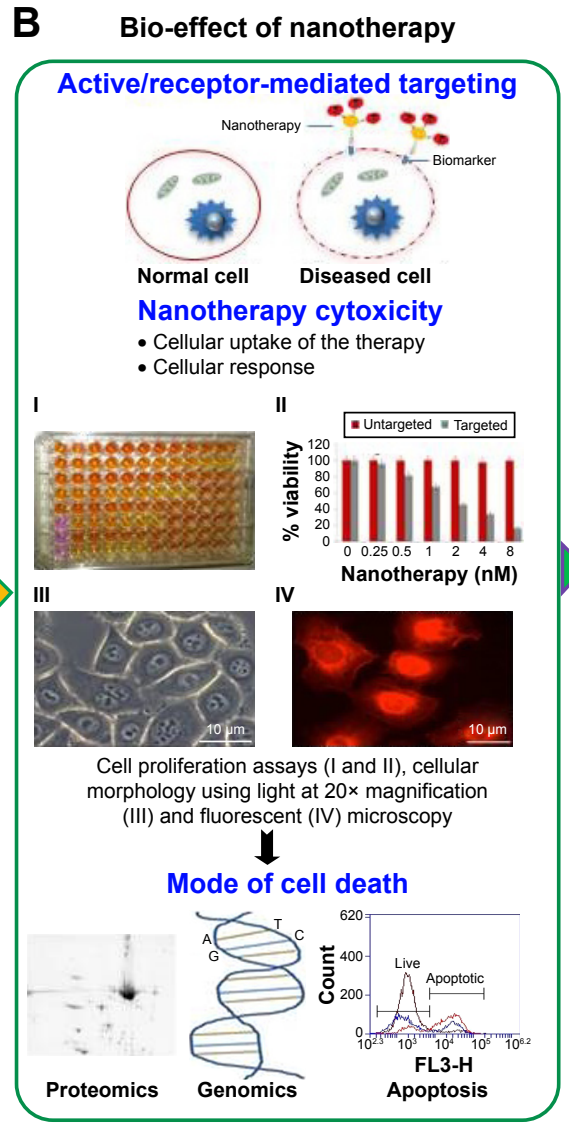

C

In vivo cytoxicity

Targeted nanotherapy

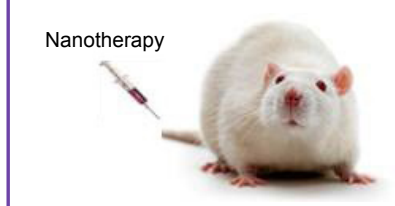

Diet-induced obese rats

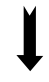

Toxicity assays

Blood and tissue sampling

- NP biodistribution

- Immune response

- Clearance

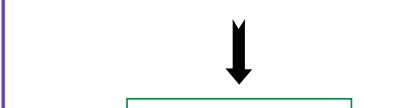

In vivo imaging

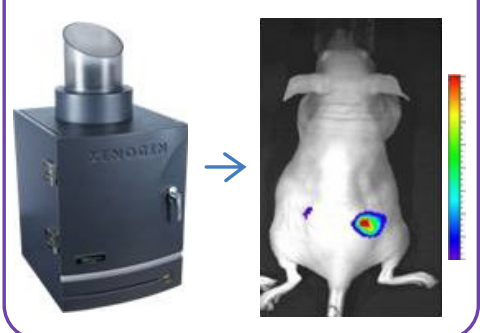

Figure 3 Initial steps in the development and assessment of targeted nanotherapy in obesity.

Notes: Preclinical phase in nanotherapy development involves synthesis, functionalization, and characterization of NP conjugates (A). The efficacy and toxicity of the nanotherapy is tested first in vitro using molecular techniques (B) followed by in vivo models of the disease (C).

Abbreviations: NP, nanoparticle; AuNPs, gold nanoparticles; TEM, transmission electron microscopy.

The beneficial effect of PHB-targeted nanotherapy in obesity treatment is summarized in Table 2 . The researchers demonstrated that when AHP (PHB-targeting ligand) and KLA (pro-apoptotic peptide) are attached to the NPs, the drug's efficacy is enhanced when compared to AHP-KLA biconjugate. The same effect was reported and reproducible in mice and rats using different nanocarriers. PHB has been used as a vascular marker since its discovery in 2004, at the time AHP was used as a PHB-targeting ligand. Since then a list of interesting PHB ligands were identified, such as oncomirs (miR-361) 77 and FLs (FL3 and 37) ${ }^{80,81}$ which showed more or less the same effects as AHP.

In obesity, the widely used ligand is AHP which demonstrated high specificity for PHB. Specificity of AHP for PHB is unquestionable, and its binding efficiency has been demonstrated in various cells that express PHB extracellular receptor (Caco-2, ${ }^{83} \mathrm{ECs},{ }^{17}$ and WAT vasculature in obese mice, ${ }^{16,17}$ rats $^{85}$ and monkeys $\left.{ }^{86}\right)$. Phage display was used to identify the receptor (PHB) which AHP binds to in vivo, ${ }^{16}$ the binding was confirmed in vitro and in vivo either alone or when attached to other molecules. And when attached to KLA, it was shown to bind and exert KLA apoptotic effects only on the WAT endothelium of obese subjects..$^{16,18}$ The specificity and sensitivity of the AHP-nanocomposite was also demonstrated in our previous study. In this study, two PHB-expressing cell lines (MCF-7 and Caco-2) and non-PHB expressing cell line (HT-29) were exposed to various AuNPs for 24 hours. Post treatment, the effects of the AHP-AuNP-KLA were more pronounced on Caco-2 cells (express $\mathrm{PHB}$ on cell surface) than the other two control cell lines as shown in Figure $4 .^{83}$ Although MCF-7 cells express PHB, ${ }^{112}$ the cells were spared from the AHPAuNP-KLA therapeutic effect as the cells express PHB in the cytoplasm. ${ }^{83}$ These data further demonstrated the specificity of the ligand to PHB, and the potential AHP and other ligands (mentioned in Table 1) might have when used for PHB-targeted therapy.

Interestingly, independent case studies (Table 2) demonstrated that by combining nanotechnology and vascular targeted therapy, the therapeutic index of the treatment was 
Table 2 PHB-targeted NP for the treatment of obesity

\begin{tabular}{|c|c|c|c|c|c|}
\hline NP type & $\begin{array}{l}\text { Composition and } \\
\text { size of NPs }(n m)\end{array}$ & Disease model & Dosage & Action of NPs & Reference \\
\hline Liposomes & PC and Chol, $105.6 \mathrm{~nm}$ & C57BL/6J mice & $\begin{array}{l}\mathrm{I} \mathrm{mg} / \mathrm{kg} \text { of } \mathrm{AHP}- \\
\mathrm{NP}-\mathrm{KLA} \text { at } 3 \text { days } \\
\text { intervals for } 30 \text { days }\end{array}$ & $\begin{array}{l}\text { - AHP delivered the encapsulated treatment } \\
\text { (KLA) to the WAT vasculature in vivo } \\
\text { - Therapy reduced serum leptin levels, } \\
\text { adipocyte size, WAT mass body weight } \\
\text { - Increased serum adiponectin } \\
\text { - Reduced ectopic fat deposited in liver } \\
\text { and muscle } \\
\text { - Reduced nonspecific uptake by RES } \\
\text { organs (liver) } \\
\text { - NPs showed enhanced activity than adipotide }\end{array}$ & 18 \\
\hline Liposomes & PC and Chol, $109.2 \mathrm{~nm}$ & $\begin{array}{l}\text { ECs from inguinal } \\
\text { AT (C57BL/6 J mice) }\end{array}$ & $62.5 \mathrm{nmol}$ lipids $/ \mathrm{mL}$ & $\begin{array}{l}\text { - AHP enhanced the selectivity of } \\
\text { encapsulated KLA }\end{array}$ & 17 \\
\hline \multirow[t]{2}{*}{ Gold NPs } & $\begin{array}{l}\text { Citrate-coated AuNPs, } \\
14 \mathrm{~nm}\end{array}$ & Caco-2 cells & $0-8 \mathrm{nM}$ & $\begin{array}{l}\text { - PHB-targeted AuNPs inhibited cell } \\
\text { proliferation } \\
\text { - Induce cell death through apoptosis }\end{array}$ & 83 \\
\hline & $\begin{array}{l}\text { Citrate-coated AuNPs, } \\
\text { I } 4 \mathrm{~nm}\end{array}$ & Wistar rats & & $\begin{array}{l}\text { - AHP delivered the AuNPs to the WAT } \\
\text { - Reduced non-specific uptake by RES organs }\end{array}$ & 85 \\
\hline $\begin{array}{l}\text { Polymeric } \\
\text { NPs }\end{array}$ & $\begin{array}{l}\text { Poly(lactic-coglycolic } \\
\text { acid)-b-poly(ethylene } \\
\text { glycol) polymer, } \\
100 \mathrm{~nm}\end{array}$ & C57BL/6 mice & $80 \mathrm{mg} / \mathrm{kg}$ & $\begin{array}{l}\text { - Enhanced expression of angiogenic and BAT } \\
\text { markers } \\
\text { - Increased angiogenesis and transformation } \\
\text { of WAT into BAT } \\
\text { - Inhibit weight gain } \\
\text { - Reduced levels of chol, TAGs, and insulin }\end{array}$ & 108 \\
\hline
\end{tabular}

Abbreviations: AHP, adipose-homing peptide; KLA, ${ }_{D}(\mathrm{KLAKLAK})_{2}$; NP, nanoparticle; ECs, endothelial cells; AT, adipose tissue; PC, phosphatidylcholine; Chol, cholesterol; RES, reticuloendothelial system; BAT, brown adipose tissue; WAT, white adipose tissue; TAGs, triacylglycerols; AuNPs, gold nanoparticles; PHB, prohibitin.

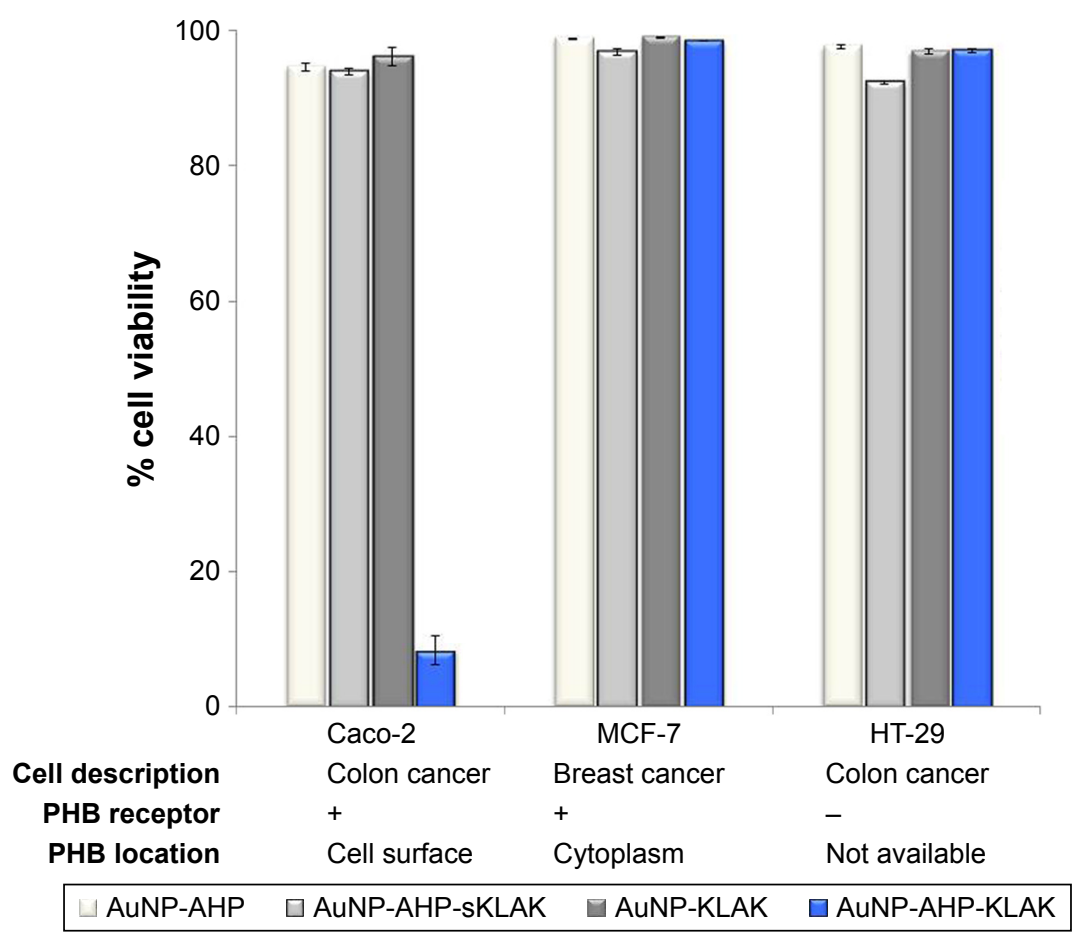

Figure 4 Specificity of PHB-targeted nanotherapy for extracellular PHB-expressing cells.

Notes: Data adapted from Sibuyi et al. ${ }^{83}$ The three cell lines were exposed to $8 \mathrm{nM}$ targeted and untargeted AuNPs with and without KLA peptide. Cell viability was assessed 24 hours post treatment.

Abbreviations: AuNP, gold nanoparticles; AHP, adipose-homing peptide; KLA, (KLAKLAK); ${ }_{5}$ KLA, scrambled KLA peptide; AuNP-AHP, AHP targeted AuNP; AuNPAHP-KLA, AuNP with AHP and a pro-apoptotic peptide; AuNP-AHP-SKLA, AuNP with AHP and a scrambled peptide; AuNP-KLA, AuNP with a pro-apoptotic peptide; PHB, prohibitin; +, present; -, absent. 
enhanced. Similar effects were shown when various NP systems were used, ranging from AuNPs, ${ }^{85}$ liposomes, ${ }^{1,17}$ and polymeric NPs. ${ }^{108}$ As such, PHB-targeted nanotherapy could be the key to combat obesity and obesity-associated diseases (cancer, CVDs, and diabetes). PHB proved to be a key factor that links these diseases, ${ }^{76}$ as such the therapy can be useful in situations where an obese patient suffers from secondary diseases. The PHB-targeted nanotherapy case studies shown in Table 2 highlight the potential and feasibility of vascular-targeted nanotherapy for the treatment of obesity. The case studies for PHB-targeted nanotherapy in obesity are discussed below:

\section{Case study I: KLA-encapsulated liposomes for PHB targeted delivery \\ NP description}

Liposomes were synthesized from phosphatidylcholine and cholesterol (Chol). A therapeutic peptide (KLA) was encapsulated within the liposomes, and the targeting peptide (AHP) was attached on the liposomal surface. ${ }^{84}$

\section{Therapeutic effect}

KLA was used as a therapeutic agent. It induced apoptosis once internalized by ECs and inhibit weight gain in dietinduced obese mice. ${ }^{16}$

\section{Action of targeted liposomes}

In vitro, the AHP-targeted nanocarrier was specifically taken up by ECs isolated from inguinal WAT obtained from obese mice when compared to EC cell lines derived from brain and fetal lung. ${ }^{84}$ In vivo, AHP-targeted liposomes accumulated in the WAT vasculature. Surprisingly, the NPs without a targeting peptide were also detected in the WAT vasculature as well as angiogenic clusters of obese adipocyte, an indication that the NPs are also taken up via EPR effect through passive targeting. ${ }^{18}$ PHB-mediated uptake of the NPs by ECs resulted in significantly reduced body weight of diet-induced obese mice after 18 days of treatment. The efficacy of the NP conjugate was greatly enhanced with $14 \%$ reduction in animal body weight compared with $5 \%$ of AHP-KLA (AHP conjugated to KLA) on its own. Body weight reduction in mice treated with NP-conjugate (AHP attached to KLA-encapsulated liposomes) was accompanied by reduced levels of leptin, adipocyte size, macrophage content, adipogenic/angiogenic clusters, reduced ectopic fat deposits in liver and muscle, and increased levels of adiponectin. Subcutaneous and epididymal WAT mass was also reduced. All these changes were not evident in mice treated with AHP-KLA for the same duration. ${ }^{18}$

\section{Case study 2:AHP-targeted delivery of AuNPs to $\mathrm{PHB}$ in obese rats \\ NP description}

AuNPs were synthesized following Turkevich method, polyethylene glycol (PEG) was used to passivate the NPs. AHP was attached to the surface of the NPs for targeted delivery to $\mathrm{PHB}{ }^{85}$

\section{Therapeutic effect}

AHP-AuNPs were designed for targeted delivery in the WAT vasculature of obese rats, and the biodistribution of PHBtargeted AuNP was analyzed 24 hours post treatment. ${ }^{85}$

\section{Action of NP biconjugate}

AHP enhanced the uptake and accumulation of the AuNPs by the WATs of diet-induced obese Wistar rats after 24 hours. Targeted AuNPs showed reduced non-specific uptake by reticuloendothelial system organs compared with non-targeted AuNPs. Non-targeted NPs accumulated mostly in the liver, spleen, lungs, kidneys, and pancreas, whereas AHP-targeted NPs accumulated in the WAT depots (inguinal, perirenal, retroperitoneal, mesenteric, and epidydimal). Similar effects were observed in vitro, where high concentrations of gold were detected on cells treated with AHP-AuNPs. ${ }^{85}$ The findings indicated that the AHP-AuNP preferentially bound to PHB expressing cells (Caco-2 $2^{83,85}$ and vascular ECs from WATs). ${ }^{85}$

\section{Case study 3: vascular-targeted polymeric NPs for the transformation of WAT to BAT NP description}

Biodegradable polymeric NPs were made from a poly(lactidecoglycolide)- $b$-PEG copolymer. Therapeutic compounds, rosiglitazone (Rosi), and 16,16-dimethyl prostaglandin E2 (PGE2) analogs were encapsulated within the NPs. Vascular targeting peptides iRGD (amino acid sequence: CRGDK/ RGPD/EC) and AHP were attached to the surface. AHP and $i R G D$ recognize $P H B$ and integrin $\alpha v \beta 3 / \beta 5$ receptors, respectively. The iRGD peptide is further cleaved into the CRGDK fragment which then binds to neuropilin-1; CRGDK increases uptake and internalization of the drug-loaded NPs into the local tissues. ${ }^{108}$

\section{Therapeutic effect}

Rosi (Avandia) is used for the treatment of T2D, either alone or in combination with other drugs. ${ }^{113}$ It binds and activates PPAR- $\gamma$ receptors in the WAT, and this leads to the increase in insulin sensitivity. Both Rosi and PGE2 analogs were used to induce angiogenesis and transformation of WAT to 
BAT, in order to reduce body weight in obese mice. Rosi and PGE2 analogs act on PPAR- $\gamma$ and prostaglandin receptor, respectively, and increase the expression of uncoupling proteins (UCPs) and transform WAT to BAT. ${ }^{108}$

\section{Action of polymeric NPs}

AHP and iRGD-targeted NPs home to their respective targets and deliver their cargo (Rosi and PGE2) within the WAT vasculature. Treatment of stromal vascular fractions with Rosi and Rosi-NPs stimulated expression of integrin $\alpha v \beta 3 / \beta 5$ at RNA and protein levels in vitro. In the WAT, Rosi induced transformation of the tissue into BAT and increased angiogenesis in vivo. Although food intake remained the same for all the groups, the targeted NPs inhibited body weight gain in mice by $10 \%$ after 25 days of treatment. Phenotypic changes observed in inguinal and epididymal tissues of mice exposed to targeted NPs included the intense reddish-brown color development, shrinkage of adipocytes, increase in number of blood vessels, and transformation of white adipocytes to brown. Compared to untreated and the free-drug-treated mice, treatment with Rosi and PGE2-loaded NPs reduced serum levels of Chol, TAGs, and insulin. ${ }^{108}$ Therefore, this indicated that obesity can be reduced by coupling vasculature-targeted nanomedicine and AT transformation.

Interestingly, BAT is thermogenically active and capable of increasing energy expenditure by $\sim 20 \%$ while an individual is at rest. Thus, activation of BAT or transformation of WAT to BAT presents another therapeutic target for obesity. Through cold exposure or stimulation of the sympathetic nervous system, white adipocytes can be converted into brown-like (also called "beige" or "brite") adipocytes which have similar activities as BAT. ${ }^{114}$ The beige adipocytes can generate heat that in turn increases energy expenditure. This thermogenic activity is attributed to the mitochondrial UCP-1 which is expressed mostly by the brown adipocytes, and to a lesser extent the beige adipocytes. ${ }^{115}$ Browning of WAT can also be achieved by using thermogenic drugs such as thyroid hormone receptor ${ }^{116}$ and $\beta$-adrenergic receptor agonists. ${ }^{117}$ Transformation of white adipocytes to beige adipocytes is accompanied by increased metabolic rate, decreased fat mass, ${ }^{116}$ increased glucose uptake, and improved insulin sensitivity. ${ }^{108,117}$

In summary, the three case studies demonstrate that vascular targeted strategies in conjunction with nanotechnology have potential for the treatment of obesity and its comorbidities. ${ }^{17,18,77,85,108}$ This vascular-targeted strategy has more benefits when compared to the targeted therapy alone, some of the benefits are summarized in Box 1. Targeted drug delivery coupled with nanotechnology increased the
Box I Beneficial effects of vascular targeted nanotherapy in obesity

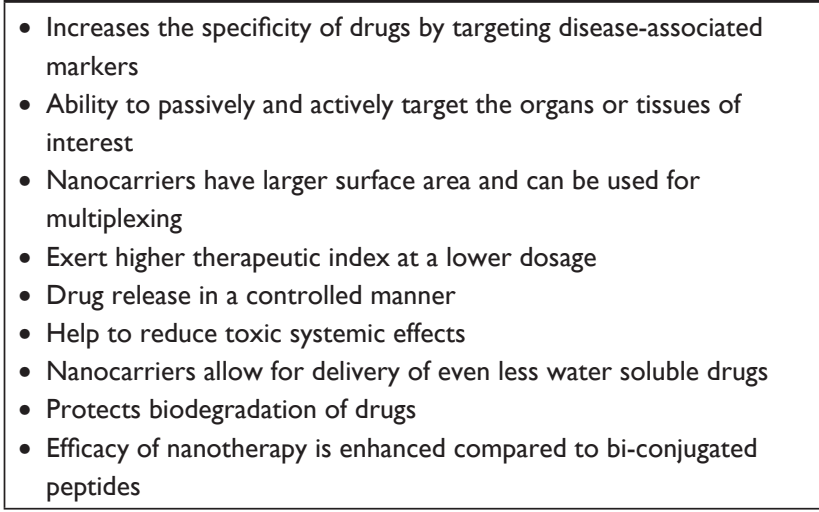

selectivity and sensitivity of the treatment, with minimal bystander toxicity effects. Candidate drugs for this strategy are not limited to the ones mentioned in this review, but other anti-obesity drugs (current or withdrawn) can also be loaded into the nanocarriers for disease treatment. In fact, multiple molecules can be incorporated into one NP due to their larger surface area. Withdrawn drugs with anti-obesity effects could be revived by this novel, attractive, and plausible strategy for the treatment of obesity. ${ }^{6,17,18,108}$ Strategies that manipulate angiogenesis, such as anti-angiogenic inhibitors and angiogenesis activators not only reduce body weight, but also inhibit adipogenesis and ectopic fat deposition, improve insulin sensitivity, and normalize the body's metabolic/physiological functions. ${ }^{18,108}$ The use of nanocarriers in combination with active targeting emerge as safer and efficient vehicles for drug delivery and offer dual targeting capability. The nanosystems can significantly enhance the drug's availability to target organs or tissues by increasing the drug's EPR effect, retention time and accumulation in the diseased organs. Targeted nanotherapy showed improved and exciting clinical benefits in cancer therapy..$^{99,109,110}$ The three case studies discussed in the review also demonstrate the strategy's potential for treatment of obesity ${ }^{17,18,98}$ and could potentially pave the way toward improving the treatment of obesity and its related metabolic diseases.

\section{Conclusion}

The current anti-obesity drugs are limited by short circulation time, insolubility, and non-selectivity of the drugs, which in turn reduce the efficacy of the drugs. ${ }^{6,47}$ More significant, however, are the bystander toxicity effects to healthy tissues that have led to the discontinuation of many anti-obesity drugs. ${ }^{6,10,12-15}$ This review shows that targeted therapeutic strategies can be used to overcome these 
drawbacks. Targeted therapy could be based on the use of homing peptides, antibodies, or aptamers that are specific for disease-associated biomarkers. Active targeting can help confine the effects of drugs only on the diseased cells, while sparing the normal cells. This will increase the efficacy of the treatment and reduce toxicity toward non-diseased cells. Vascular targeting showed promising results in the reversal of diet-induced obesity in mice ${ }^{16}$ and non-human primates. ${ }^{86}$ Therefore, targeted nanotherapy offers a great opportunity for the treatment of obesity through increased selectivity and sensitivity of the treatment. The concept of targeted drug delivery coupled with nanotechnology is thus an attractive and plausible strategy for the treatment of obesity. ${ }^{17,18,83,85}$

\section{Acknowledgments}

The authors would like to acknowledge South African Department of Science and Technology/Mintek Nanotechnology Innovation Centre, National Research Foundation, and the University of the Western Cape for their financial support.

\section{Disclosure}

The authors report no conflicts of interest in this work.

\section{References}

1. Apovian CM, Riffenburg KM. Perspectives on the global obesity epidemic. Curr Opin Endocrinol Diabetes Obes. 2017;24(5):307-309.

2. Eckel RH, Kahn SE, Ferrannini E, et al. Obesity and Type 2 Diabetes: What can be unified and what needs to be individualized? J Clin Endocrinol Metab. 2011;96(6):1654-1663.

3. Lavie CJ, Milani RV, Ventura HO. Obesity and cardiovascular disease: risk factor, paradox, and impact of weight loss. $\mathrm{J} \mathrm{Am} \mathrm{Coll} \mathrm{Cardiol}$. 2009;53(21):1925-1932.

4. Bray GA. The underlying basis for obesity: relationship to cancer. J Nutr. 2002;132(11 Suppl):3451S-3455S.

5. Narkiewicz K. Obesity and hypertension - the issue is more complex than we thought. Nephrology Dialysis Transplantation. 2006;21(2): 264-267.

6. Bray GA. A concise review on the therapeutics of obesity. Nutrition. 2000;16(10):953-960.

7. Cannon CP, Kumar A. Treatment of overweight and obesity: Lifestyle, pharmacologic, and surgical options. Clin Cornerstone. 2009; 9(4):55-71.

8. van Gaal L, Dirinck E. Pharmacological Approaches in the Treatment and Maintenance of Weight Loss. Diabetes Care. 2016;39(Suppl 2): S260-S267.

9. Adan RAH. Mechanisms underlying current and future anti-obesity drugs. Trends Neurosci. 2013;36(2):133-140.

10. Kang JG, Park C-Y. Anti-obesity drugs: a review about their effects and safety. Diabetes Metab J. 2012;36(1):13-25.

11. Ioannides-Demos LL, Piccenna L, Mcneil JJ. Pharmacotherapies for obesity: past, current, and future therapies. J Obes. 2011;2011(15):1-18.

12. Williams G. Withdrawal of sibutramine in Europe. BMJ. 2010;340(3): c824.

13. Abbot. Abbott to voluntarily withdraw Meridia ${ }^{\circledR}$ (Sibutramine) in the U.S.; October 10, 2010. Available from: http://www. disabled-world.com/medical/recalls/meridia-sibutramine-withdraw. php\#ixzz28ih0rGMM. Accessed November 30, 2017.
14. Medsafe. Withdrawal of Sibutramine (Reductil) in New Zealand; October 11, 2010. Available from: http://www.medsafe.govt.nz/hot/ media/2010/SibutramineOct2010.asp. Accessed November 30, 2017.

15. Therapeutic Goods Administration. Sibutramine (Reductil) - withdrawal in Australia; October 8, 2010. Available from: http://www.tga. gov.au/safety/alerts-medicine-sibutramine-101008.htm. Accessed November 30, 2017.

16. Kolonin MG, Saha PK, Chan L, Pasqualini R, Arap W. Reversal of obesity by targeted ablation of adipose tissue. Nat Med. 2004;10(6): 625-632.

17. Hossen MN, Kajimoto K, Akita H, Hyodo M, Ishitsuka T, Harashima H. Ligand-based targeted delivery of a peptide modified nanocarrier to endothelial cells in adipose tissue. J Control Release. 2010;147(2): 261-268.

18. Hossen MN, Kajimoto K, Akita H, Hyodo M, Harashima H. A comparative study between nanoparticle-targeted therapeutics and bioconjugates as obesity medication. J Control Release. 2013;171(2):104-112.

19. Arner P. Obesity - a genetic disease of adipose tissue? Br J Nutr. 2000;83(S1):S9-S16.

20. O’Rahilly S, Farooqi IS, Gsh Y, Challis BG. Human obesity-lessons from monogenic disorders. Endocrinology. 2003;144:3757-3764.

21. Trayhurn P. Adipocyte biology. Obes Rev. 2007;8(s1):41-44.

22. Racette SB, Deusinger SS, Deusinger R. Obesity: Overview of prevalence, etiology, and treatment. Physical Therapy. 2003;83(3):276-288.

23. Pulgarón ER. Childhood obesity: a review of increased risk for physical and psychological comorbidities. Clin Ther. 2013;35(1): A18-A32.

24. World Health Organization (WHO). Global Health Observatory (GHO) data; 2017. Available from: http://www.who.int/gho/ncd/risk_factors/ overweight_obesity/obesity_adults/en/. Accessed June 4, 2018.

25. World Health Organization (WHO). Global Health Observatory data repository. Prevalence of obesity among adults, BMI $\geq 30$, age-standardized. Estimates by WHO region. Available from: http:// apps.who.int/gho/data/view.main.REGION2480A?lang=en. Accessed June 4, 2018.

26. Department of Health (South Africa). World Obesity Day 2016; 2016. Available from: http://www.health.gov.za/index.php/gf-tbprogram/323-world-obesity-day-2016. Accessed November 20, 2017.

27. Iwen KAH, Perwitz N, Kraus D, Fasshauer M, Klein J. Putting fat cells onto the road map to novel therapeutic strategies. Discov Med. 2006;6:75-81.

28. Gustafson B, Hammarstedt A, Andersson CX, Smith U, Tissue IA. A Culprit Underlying the Metabolic Syndrome and Atherosclerosis. Arterioscler Thromb Vasc Biol. 2007;27:2276-2283.

29. Hauner $\mathrm{H}$. The new concept of adipose tissue function. Physiol Behav. 2004;83(4):653-658.

30. Hausman DB, Digirolamo M, Bartness TJ, Hausman GJ, Martin RJ. The biology of white adipocyte proliferation. Obes Rev. 2001;2(4): 239-254.

31. Vázquez-Vela MEF, Torres $\mathrm{N}$, Tovar AR. White adipose tissue as endocrine organ and its role in obesity. Arch Med Res. 2008;39(8): $715-728$.

32. Bozaoglu K, Curran JE, Stocker CJ, et al. Chemerin, a Novel Adipokine in the Regulation of Angiogenesis. J Clin Endocrinol Metab. 2010;95(5):2476-2485.

33. Hajer GR, van Haeften TW, Visseren FLJ. Adipose tissue dysfunction in obesity, diabetes, and vascular diseases. Eur Heart J. 2008; 29(24):2959-2971.

34. Krug AW, Ehrhart-Bornstein M. Newly discovered endocrine functions of white adipose tissue: possible relevance in obesity-related diseases. Cell Mol Life Sci. 2005;62(12):1359-1362.

35. Sethi JK, Vidal-Puig AJ. Adipose tissue function and plasticity orchestrate nutritional adaptation. J Lipid Res. 2007;48:1253-1262.

36. Guerre-Millo M. Adipose tissue and adipokines: for better or worse. Diabetes Metab. 2004;30(1):13-19.

37. Lefterova MI, Lazar MA. New developments in adipogenesis. Trends in Endocrinol Metab. 2009;20(3):107-114. 
38. Diabetes Prevention Program Research Group. Reduction in the Incidence of Type 2 Diabetes with Lifestyle Intervention or Metformin. N Engl J Med Overseas Ed. 2002;346(6):393-403.

39. Klein S, Sheard NF, Pi-Sunyer X, et al. Weight management through lifestyle modification for the prevention and management of type 2 diabetes: rationale and strategies. Diabetes Care. 2004;27:2067-2073.

40. Wadden TA, Mcguckin BG, Rothman RA, Sargent SL. Lifestyle modification in the management of obesity. J Gastrointest Surg. 2003;7(4): $452-463$.

41. Hainer V, Toplak H, Mitrakou A. Treatment modalities of obesity. Diabetes Care. 2008;31:S269-S277.

42. Demaria EJ. Bariatric Surgery for Morbid Obesity. $N$ Engl J Med Overseas Ed. 2007;356(21):2176-2183.

43. Fisher BL, Schauer P. Medical and surgical options in the treatment of severe obesity. Am J Surg. 2002;184(6B):S9-S16.

44. Foster-Schubert KE, Cummings DE. Emerging Therapeutic Strategies for Obesity. Endocr Rev. 2006;27(7):779-793.

45. Abell TL, Minocha A. Gastrointestinal complications of bariatric surgery: diagnosis and therapy. Am J Med Sci. 2006;331(4):214-218.

46. Berger JR. The Neurological Complications of Bariatric Surgery. Arch Neurol. 2004;61(8):1185-1189.

47. St. Jeor ST, Hayman LL, Daniels SR. Prevention conference VII: obesity, a worldwide epidemic related to heart disease and stroke: Group II: age-dependent risk factors for obesity and comorbidities. Circulation. 2004;110(18):e471-e475.

48. Gupta K, Zhang J. Angiogenesis: a curse or cure? Postgrad Med J. 2005;81(954):236-242.

49. Griffioen AW, Molema G. Angiogenesis: potentials for pharmacologic intervention in the treatment of cancer, cardiovascular diseases, and chronic inflammation. Pharmacol Rev. 2000;52:237-267.

50. Liekens S, de Clercq E, Neyts J. Angiogenesis: regulators and clinical applications. Biochem Pharmacol. 2001;61(3):253-270.

51. Goligorsky MS. Endothelial cell dysfunction: can't live with it, how to live without it. Am J Physiol Renal Physiol. 2005;288(5):F871-F880.

52. Sengenès C, Miranville A, Lolmède K, Curat CA, Bouloumié A. The role of endothelial cells in inflamed adipose tissue. J Intern Med. 2007; 262(4):415-421.

53. Caballero AE. Endothelial dysfunction in obesity and insulin resistance: a road to diabetes and heart disease. Obes Res. 2003;11(11):1278-1289.

54. Singh DK, Winocour P, Farrington K. Review: Endothelial cell dysfunction, medial arterial calcification and osteoprotegerin in diabetes. Br J Diabetes Vasc Dis. 2010;10(2):71-77.

55. Mather KJ, Steinberg HO, Baron AD. Weight loss and endothelial function in obesity. Diabetes Care. 2003;26(6):1927-1928.

56. Mueller J, Gaertner FC, Blechert B, Janssen KP, Essler M. Targeting of tumor blood vessels: a phage-displayed tumor-homing peptide specifically binds to matrix metalloproteinase-2-processed collagen IV and blocks angiogenesis in vivo. Mol Cancer Res. 2009;7(7):1078-1085.

57. Wang Z, Dabrosin C, Yin X, et al. Broad targeting of angiogenesis for cancer prevention and therapy. Semin Cancer Biol. 2015;35:S224-S243.

58. Ning Y-M, Gulley JL, Arlen PM, et al. Phase II trial of bevacizumab, thalidomide, docetaxel, and prednisone in patients with metastatic castration-resistant prostate cancer. J Clin Oncol. 2010;28(12): 2070-2076.

59. Rosen L. Antiangiogenic strategies and agents in clinical trials. Oncologist. 2000;5(90001):20-27.

60. Tassi E, Wellstein A. Tumor Angiogenesis: Initiation and Targeting Therapeutic Targeting of an FGF-Binding Protein, an Angiogenic Switch Molecule, and Indicator of Early Stages of Gastrointestinal Adenocarcinomas. Cancer Res Treat. 2006;38(4):189-197.

61. Okaji Y, Tsuno NH, Saito S, et al. Vaccines targeting tumour angiogenesis - a novel strategy for cancer immunotherapy. Eur J Surg Oncol. 2006;32(4):363-370.

62. Goto H, Yano S, Matsumori Y, Ogawa H, Blakey DC, Sone S. Sensitization of tumor-associated endothelial cell apoptosis by the novel vascular-targeting agent ZD6126 in combination with cisplatin. Clin Cancer Res. 2004;10(22):7671-7676.
63. Liu Y, Deisseroth A. Tumor vascular targeting therapy with viral vectors. Blood. 2006;107(8):3027-3033.

64. Carmeliet P, Jain RK. Angiogenesis in cancer and other diseases. Nature. 2000;407(6801):249-257.

65. Daquinag AC, Zhang Y, Kolonin MG. Vascular targeting of adipose tissue as an anti-obesity approach. Trends Pharmacol Sci. 2011;32(5): 300-307.

66. Cao Y. Adipose tissue angiogenesis as a therapeutic target for obesity and metabolic diseases. Nat Rev Drug Discov. 2010;9(2):107-115.

67. Christiaens V, Lijnen HR. Angiogenesis and development of adipose tissue. Mol Cell Endocrinol. 2010;318(1-2):2-9.

68. Bråkenhielm E, Cao R, Gao B. Angiogenesis inhibitor, TNP-470, prevents diet-induced and genetic obesity in mice. Circ Res. 2004; 94(12):1579-1588

69. Rupnick MA, Panigrahy D, Zhang CY, et al. Adipose tissue mass can be regulated through the vasculature. Proc Natl Acad Sci US A. 2002; 99(16):10730-10735.

70. Kim YM, An JJ, Jin Y-J, et al. Assessment of the anti-obesity effects of the TNP-470 analog, CKD-732. J Mol Endocrinol. 2007;38(4): 455-465.

71. Tam J, Duda DG, Perentes JY, Quadri RS, Fukumura D, Jain RK. Blockade of VEGFR2 and not VEGFR1 can limit diet-induced fat tissue expansion: role of local versus bone marrow-derived endothelial cells. PLoS One. 2009;4(3):e4974.

72. Thuaud F, Ribeiro N, Nebigil CG, Désaubry L. Prohibitin ligands in cell death and survival: mode of action and therapeutic potential. Chem Biol. 2013;20(3):316-331.

73. Koushyar S, Jiang WG, Dart DA. Unveiling the potential of prohibitin in cancer. Cancer Lett. 2015;369(2):316-322.

74. Mishra S, Nyomba BLG. Prohibitin - At the crossroads of obesity-linked diabetes and cancer. Exp Biol Med. 2017;242(11):1170-1177.

75. Ande SR, Nguyen KH, Nyomba BLG, Mishra S. Prohibitin in Adipose and Immune Functions. Trends Endocrinol Metab. 2016;27(8): 531-541.

76. Chowdhury I, Thompson WE, Thomas K. Prohibitins role in cellular survival through Ras-Raf-MEK-ERK pathway. $J$ Cell Physiol. 2014;229(8):998-1004.

77. Dong WQ, Chao M, Lu QH, et al. Prohibitin overexpression improves myocardial function in diabetic cardiomyopathy. Oncotarget. 2016; 7(1):66-80.

78. Giannotta M, Fragassi G, Tamburro A, Vanessa C, Luini A, Sallese M. Prohibitin: A novel molecular player in KDEL receptor signalling. Biomed Res Int. 2015;2015(7):319454-13.

79. Cao Y, Liang H, Zhang F, et al. Prohibitin overexpression predicts poor prognosis and promotes cell proliferation and invasion through ERK pathway activation in gallbladder cancer. J Exp Clin Cancer Res. 2016;35(35):68.

80. Han J, Zhao Q, Basmadjian C, Désaubry L, Theiss AL. Flavaglines ameliorate experimental colitis and protect against intestinal epithelial cell apoptosis and mitochondrial dysfunction. Inflamm Bowel Dis. 2016;22(1):55-67.

81. Basmadjian C, Thuaud F, Ribeiro N, Désaubry L. Flavaglines: potent anticancer drugs that target prohibitins and the helicase eIF4A. Future Med Chem. 2013;5(18):2185-2197.

82. Chen D, Chen F, Lu X, et al. Identification of prohibitin as a potential biomarker for colorectal carcinoma based on proteomics technology. Int J Oncol. 2010;37(2):355-365.

83. Sibuyi NR, Thovhogi N, Gabuza KB, et al. Peptide-functionalized nanoparticles for the selective induction of apoptosis in target cells. Nanomedicine. 2017;12(14):1631-1645.

84. Hossen MN, Kajimoto K, Akita H, Hyodo M, Harashima H. Vasculartargeted nanotherapy for obesity: Unexpected passive targeting mechanism to obese fat for the enhancement of active drug delivery. J Control Release. 2012;163(2):101-110.

85. Thovhogi N, Sibuyi N, Meyer M, Onani M, Madiehe A. Targeted delivery using peptide-functionalised gold nanoparticles to white adipose tissues of obese rats. J Nanopart Res. 2015;17(2):112. 
86. Barnhart KF, Christianson DR, Hanley PW, et al. A peptidomimetic targeting white fat causes weight loss and improved insulin resistance in obese monkeys. Sci Transl Med. 2011;3(108):108ra112-112.

87. Ruoslahti E. Targeting tumor vasculature with homing peptides from phage display. Semin Cancer Biol. 2000;10(6):435-442.

88. Strimbu K, Tavel JA. What are biomarkers? Curr Opin HIV AIDS. 2010; 5(6):463-466.

89. Byrnes SA, Weigl BH. Selecting analytical biomarkers for diagnostic applications: a first principles approach. Expert Rev Mol Diagn. 2018; 18(1):19-26.

90. Gerber DE. Targeted therapies: A new generation of cancer treatment. Am Fam Physician. 2008;77:311-319.

91. Hilgenbrink AR, Low PS. Folate receptor-mediated drug targeting: from therapeutics to diagnostics. J Pharm Sci. 2005;94(10):2135-2146.

92. Pal D, Nayak AK. Nanotechnology for targeted delivery in cancer therapeutics. Int J Pharm Sci Rev Res. 2010;1:1-7.

93. Provenzale JM, Silva GA. Uses of nanoparticles for central nervous system imaging and therapy. AJNR Am J Neuroradiol. 2009;30(7): 1293-1301.

94. Moghimi SM, Hunter AC, Murray JC. Nanomedicine: current status and future prospects. The FASEB Journal. 2005;19(3):311-330.

95. Hardman R. A toxicologic review of quantum dots: toxicity depends on physicochemical and environmental factors. Environ Health Perspect. 2006;114(2):165-172.

96. de Jong WH, Hagens WI, Krystek P, Burger MC, Sips AJAM, Geertsma RE. Particle size-dependent organ distribution of gold nanoparticles after intravenous administration. Biomaterials. 2008; 29(12):1912-1919.

97. Praetorius N, Mandal T. Engineered nanoparticles in cancer therapy. Recent Pat Drug Deliv Formul. 2007;1(1):37-51.

98. Shang L, Nienhaus K, Nienhaus GU. Engineered nanoparticles interacting with cells: size matters. J Nanobiotechnology. 2014;1477(3155):12-15.

99. Bobo D, Robinson KJ, Islam J, Thurecht KJ, Corrie SR. Nanoparticlebased medicines: A review of FDA-approved materials and clinical trials to date. Pharm Res. 2016;33(10):2373-2387.

100. Wang EC, Wang AZ. Nanoparticles and their applications in cell and molecular biology. Integr Biol. 2014;6(1):9-26.

101. Kingsley JD, Dou H, Morehead J, Rabinow B, Gendelman HE, Destache CJ. Nanotechnology: A Focus on Nanoparticles as a Drug Delivery System. J Neuroimmune Pharmacol. 2006;1(3):340-350.

102. Bazak R, Houri M, El Achy S, Kamel S, Refaat T. Cancer active targeting by nanoparticles: a comprehensive review of literature. J Cancer Res Clin Oncol. 2015;141(5):769-784.
103. Yezhelyev MV, Gao X, Xing Y, Al-Hajj A, Nie S, O’Regan RM. Emerging use of nanoparticles in diagnosis and treatment of breast cancer. Lancet Oncol. 2006;7(8):657-667.

104. Ojeda R, de Paz JL, Barrientos AG, Martín-Lomas M, Penadés S. Preparation of multifunctional glyconanoparticles as a platform for potential carbohydrate-based anticancer vaccines. Carbohydr Res. 2007;342(3-4):448-459.

105. Tomuleasa C, Soritau O, Orza A, et al. Gold nanoparticles conjugated with cisplatin/doxorubicin/capecitabine lower the chemoresistance of hepatocellular carcinoma-derived cancer cells. J Gastrointestin Liver Dis. 2012;21:187-196.

106. Brigger I, Dubernet C, Couvreur P. Nanoparticles in cancer therapy and diagnosis. Adv Drug Deliv Rev. 2002;54(5):631-651.

107. Caruthers SD, Wickline SA, Lanza GM. Nanotechnological applications in medicine. Curr Opin Biotechnol. 2007;18(1):26-30.

108. Xue Y, Xu X, Zhang XQ, Farokhzad OC, Langer R. Preventing diet-induced obesity in mice by adipose tissue transformation and angiogenesis using targeted nanoparticles. Proc Natl Acad Sci US A. 2016;113(20):5552-5557.

109. Anselmo AC, Mitragotri S. Nanoparticles in the clinic. Bioeng Transl Med. 2016;1(1):10-29.

110. Pillai G. Nanomedicines for cancer therapy: An update of FDA approved and those under various stages of development. SOJ Pharm Pharm Sci. 2014;1(2):13.

111. Anselmo AC, Mitragotri S. A Review of clinical translation of inorganic nanoparticles. Aaps J. 2015;17(5):1041-1054.

112. Peng X, Mehta RG. Differential expression of prohibitin is correlated with dual action of Vitamin D as a proliferative and antiproliferative hormone in breast epithelial cells. J Steroid Biochem Mol Biol. 2007;103(3-5):446-450.

113. Malinowski JM, Bolesta S. Rosiglitazone in the treatment of type 2 diabetes mellitus: a critical review. Clin Ther. 2000;22(10):1151-1168.

114. Lee P, Greenfield JR, Ho KK, Fulham MJ. A critical appraisal of the prevalence and metabolic significance of brown adipose tissue in adult humans. Am J Physiol Endocrinol Metab. 2010;299(4):E601-E606.

115. Wu J, Boström P, Sparks LM, et al. Beige adipocytes are a distinct type of thermogenic fat cell in mouse and human. Cell. 2012;150(2): 366-376.

116. Lin JZ, Martagón AJ, Cimini SL, et al. Pharmacological Activation of Thyroid Hormone Receptors Elicits a Functional Conversion of White to Brown Fat. Cell Rep. 2015;13(8):1528-1537.

117. Kiefer FW. The significance of beige and brown fat in humans. Endocr Connect. 2017;6(5):R70-R79.
International Journal of Nanomedicine

\section{Publish your work in this journal}

The International Journal of Nanomedicine is an international, peerreviewed journal focusing on the application of nanotechnology in diagnostics, therapeutics, and drug delivery systems throughout the biomedical field. This journal is indexed on PubMed Central,

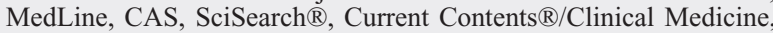

\section{Dovepress}

Journal Citation Reports/Science Edition, EMBase, Scopus and the Elsevier Bibliographic databases. The manuscript management system is completely online and includes a very quick and fair peer-review system, which is all easy to use. Visit http://www.dovepress.com/ testimonials.php to read real quotes from published authors. 